\title{
Thông tin chi tiết học phần toán tài chính TNT605
}

\author{
Trần Văn Lý
}

September 29, 2014

TRƯỜNG ĐẠI HOQC CẦN THO'

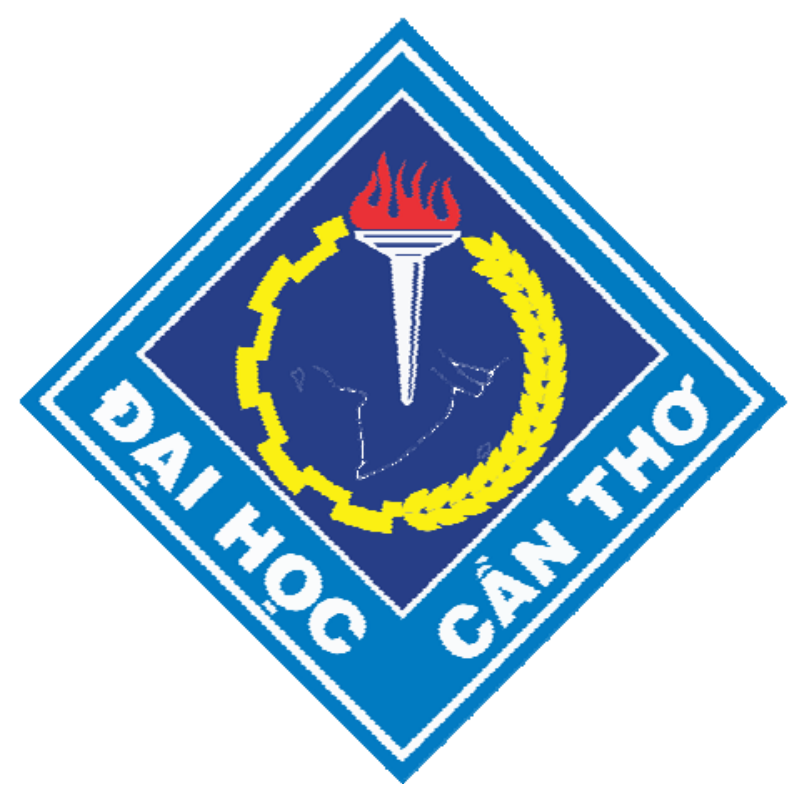

https://cns.ctu.edu.vn/96LD4AMFnN-

k050j9fqWTtN3449lqf6GRWgSehZxF0e6ccObwoytWWISFvENsXdOFtQTkBwjWIJf 354 vOjKaMA== 
BỘ GIÁO DỤC VÀ ĐÀO TẠO

TRƯỜNG ĐẠI HỌC CẦN THƠ

\section{THÔNG TIN VỀ HỌC PHẦN VÀ GIẢNG VIÊN}

1.1. Tên học phần: Toán tài chính (Financial Mathematics). Mã số TNT605

1.2. Trình độ: Thạc sĩ.

1.3. Cấu trúc học phần: Số TC: 02. (LT: 30 tiết)

1.4. Học phần tiên quyết: Giải tích ngẫu nhiên. Mã số:.

1.5. Bộ môn phụ trách giảng dạy: Toán; Khoa/Viện: KHTN.

1.6. Thông tin giảng viên:

Họ và tên Giảng viên: Trần Văn Lý.

Học hàm, học vị: Tiến sĩ.

Địa chỉ liên hệ: ĐT: 0939449 216. Email: tvly@ctu.edu.vn.

\section{MÔ TẢ HỌC PHẦN}

Học phần cung cấp cho học viên các khái niệm cơ bản về toán tài chính; ứng dụng các kiến thức của giải tích ngẫu nhiên và quá trình ngẫu nhiên vào trong các vấn đề của toán tài chính.

\section{MỤC TIÊU HỌC PHÀ̀N}

\subsection{Giới thiệu tổng quát về học phần}

Đây là học phần thuộc khối kiến thức chuyên ngành. Học phần nghiên cứu về lý thuyết độ chênh thị giá, định giá một sản phẩm phái sinh, định giá quyền chọn, lý thuyết rủi ro tín dụng, chuỗi thời gian tài chính.

\subsection{Nội dung chi tiết học phần} NộI DUNG HỌC PHẦN

\begin{tabular}{|c|c|}
\hline Chương & $\begin{array}{c}\text { Tiết } \\
\text { (LT/BT/TH) }\end{array}$ \\
\hline $\begin{array}{l}\text { Chương 1. Lý thuyết độ chênh thị giá } \\
\text { Chương này nghiên cưu các khái niệm tài chính xoay quanh quá trình } \\
\text { giá. } \\
\text { 1.1. Giá được xem như các quá trình ngẫu nhiên } \\
\text { 1.2. Nguyên lý AAO và nguyên lý Đáp ứng } \\
\text { 1.3. Các thị trường đầy đủ } \\
\text { 1.4. Xác suất rủi ro trung tính } \\
\text { Để học tốt chương này học viên tham khảo các tài liệu:[1], [3], [4]. }\end{array}$ & 8 tiết LT \\
\hline $\begin{array}{l}\text { Chương 2. Định giá một sản phẩm phái sinh } \\
\text { Giới thiệu một số dạng Quyền chọn, tiếp cận rủi ro tài chính. } \\
\text { 2.1. Định giá một Quyền Chọn và định giá một sản phẩm phái sinh } \\
\text { nói chung }\end{array}$ & 4 tiết LT \\
\hline
\end{tabular}




\begin{tabular}{|c|c|}
\hline Chưong & $\begin{array}{c}\text { Tiết } \\
\text { (LT/BT/TH) }\end{array}$ \\
\hline $\begin{array}{l}\text { 2.2. Sơ bộ về rủi ro tài chính } \\
\text { Để hoc tốt chuoong này học viên tham khảo các tài liệu [4], [2]. }\end{array}$ & \\
\hline $\begin{array}{l}\text { Chương 3. Định giá quyền chọn } \\
\text { Nghiên cưu điển hình về nội dung định giá quyền chọn. } \\
\text { 3.1. Mô hình Black-Scholes } \\
\text { 3.2. Phương trình đạo hàm riêng } \\
\text { 3.3. Mô hình Cox-Ross-Rubinstein } \\
\text { Để học tốt chuoong này học viên tham khảo các tài liệu [4], [2], [1]. }\end{array}$ & 6 tiết LT \\
\hline $\begin{array}{l}\text { Chương 4. Lý thuyết rủi ro tín dụng } \\
\text { Nghiên cứu điển hình về lý thuyết rủi ro. } \\
\text { 4.1. Mô hình Merton } \\
\text { 4.2. Hệ thống định mức rủi ro } \\
\text { 4.3. Mô hình Jarrow-Lando-Turnbull } \\
\text { 4.4. Đánh giá rủi ro tín dụng bằng phương pháp VaR } \\
\text { Để học tốt chương này học viên tham khảo các tài liệu [1], [2], [3]. }\end{array}$ & 6 tiết LT \\
\hline $\begin{array}{l}\text { Chương 5. Chuỗi thời gian tài chính } \\
\text { Giới thiệu các mô hình phân tích chuỗi thời gian sủ dụng thông dụng } \\
\text { trong tài chính. } \\
\text { 5.1. Các mô hình Gauss và Gauss có điều kiện } \\
\text { 5.2. Các mô hình tuyến tính } \\
\text { 5.3. Các mô hình phi tuyến } \\
\text { 5.4. Mô hình độ biến động ngẫu nhiên } \\
\text { Để học tốt chuoong này học viên tham khảo các tài liệu [4], [2], [1]. }\end{array}$ & 6 tiết LT \\
\hline
\end{tabular}

\section{PHƯƠNG PHÁP GIẢNG DẠY VÀ ĐÁNH GIÁ}

4.1. Phương pháp giảng dạy: Dùng phương pháp diễn giải kết hợp với phương pháp mô phỏng/minh họa số. Yêu cầu học viên tích cực tự học và nghiên cứu tài liệu.

4.2. Phương pháp đánh giá: Học viên viết tiểu luận cuối kỳ.

\section{TÀI LIỆU THAM KHẢO CỦA HỌC PHẦN}

1. Shreve,S. E. (2011), Stochastic calculus for finance II, Springer.

2. Protter, P. (1990), Stochastic Integration and differential equations, Springer-Verlag.

3. Nguyễn V. H., Vương Q. H. (2000), Các phương pháp toán học trong tài chính, NXB ĐH Quốc Gia Hà Nội.

4. Trần H. T. (2004), Nhập môn toán tài chính, NXB Khoa học và kỹ thuật. 
Duyệt của đon vị

TL. HIÊUU TRU'ỎNG TRUOỎNG KHOA/VIỆN
Ngày 29 tháng 09 năm 2014

Người biên soạn

Trần Văn Lý 


\section{TÀI LIỆ THAM KHẢO:}

1. Shreve, S. E. (2011). Stochastic calculus for finance II. Berlin: Springer.

2. Protter, P. (1990). Stochastic Integration and differential equations. Berlin: SpringerVerlag.

3. Hữu, N. V., \& Hoàng, V. Q. (2007). Các phưong pháp toán học trong tài chính. NXB Đại học Quốc gia, Hà Nội.

4. Thao, T. H. (2004). Nhập môn toán tài chính. NXB Khoa học và Kỹ thuật, Hà Nội. 